\title{
Reply to Letter: Onyx for Embolization of Life-Threatening Hemoptysis: A Promising but Luxury Embolic Agent!
}

\author{
Sebastien Bommart
}

Published online: 28 December 2011

(C) Springer Science+Business Media, LLC and the Cardiovascular and Interventional Radiological Society of Europe (CIRSE) 2011

We thank Dr. Loffroy and colleagues for their interest in our article [1]. Side effects, such as vasospasm, could limit embolization efficacy and must be taken into account when using ethylene vinyl alcohol copolymers (EVAC). This possibility was described in the "Materials and Methods" section and reported for one case in our series. This point also was commentated in the discussion. Respecting the manufacturer's recommendations, particularly about the slow rate of injection should help avoiding this phenomenon. According to some authors [2], EVAC injection can be done more quickly when the dead space of the microcatheter filled with DMSO is completely flushed. However, this is not clearly recommended for standard use due to the risk of a too high DMSO blood concentration and increased risk of cardiac and respiratory complications.

We did not discuss in detail the problem of the smell after embolization in our article, mainly because this work was focused on EVAC visualization and penetration. Moreover, in our opinion, it should not be considered as a side effect. Indeed, when we use this agent, we inform the patients about this feature beforehand. Moreover, because chest pain is frequently experienced by patients with this embolic agent, we also pharmacologically prevent chest pain during injection.

We agree with Dr. Loffroy that embolization with Onyx is effective but quite expensive. At this point in time, we are still waiting for the perfect agent to stop bleeding without short-term or late recurrences. Cyanoacrylate is proposed as a cheaper option by Dr. Loffroy. EVAC and cyanoacrylate are both liquid agents, but the risk of nontarget embolization with cyanoacrylate is clearly higher and this fact must be considered along with its specific complications. EVAC is not the panacea for bronchial artery embolization but can be used as alternative tool in particular clinical situations, especially when the bronchial artery wall is at risk of erosion. Future studies in a larger cohort of patients are now needed to evaluate the place of EVAC in the management of life-threatening hemoptysis.

Conflict of interest None.

\section{References}

1. Bommart S, Bourdin A, Giroux MF et al (2011) Transarterial ethylene vinyl alcohol copolymer visualization and penetration after embolization of life-threatening hemoptysis: technical and clinical outcomes. Cardiovasc Interv Radiol (Epub ahead of print)

2. Gandhi CD, El-Gengahy A, Cornett-Thompson OE et al (2011) The novel use of Onyx for the rapid treatment of a traumatic carotid injury. J Neurointerv Surg (Epub ahead of print)

\footnotetext{
S. Bommart $(\bowtie)$

Imagerie Médicale, Hopital Arnaud de Villeneuve,

CHU de Montpellier, Montpellier, France

e-mail: s-bommart@chu-montpellier.fr
} 